\title{
Entre o Limite e a Esperança: Relato de uma Experiência em Psicologia Institucional
}

From limit to hope:

An account of an experience on institutional

psychology

Patricia Gula \& Nadja Pinheiro

Universidade Estácio de Sá

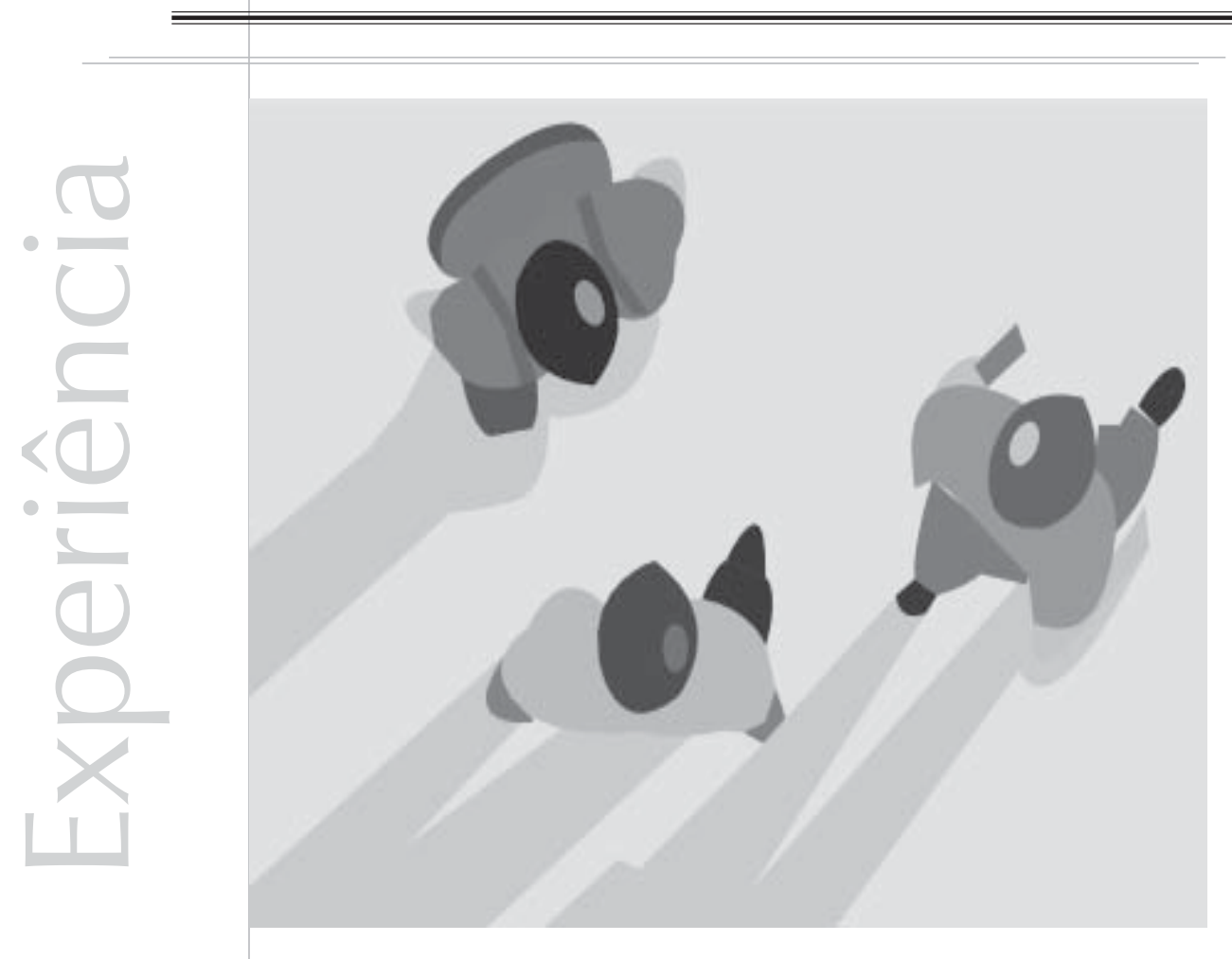


Resumo: O presente artigo propõe uma reflexão sobre o trabalho em Psicologia institucional. Utilizando-se da perspectiva teórica de Bleger, é apresentada uma experiência de trabalho desenvolvida em uma instituição localizada na cidade de Nova Friburgo, Estado do Rio de Janeiro, cujo principal propósito é profissionalizar adolescentes visando a seu ingresso no mercado de trabalho local. Como conclusão, são destacadas a importância e a pertinência do trabalho da Psicologia institucional, o qual permite uma significativa transformação tanto subjetiva, ao possibilitar, aos atores institucionais, a construção de suas próprias vidas, quanto institucional, ao tornar sua dinâmica mais flexível e menos cristalizada no exercício de um poder autoritário.

Palavras-chave: Psicologia, Psicologia institucional, instituição.

Abstract:The present paper proposes a reflection on Institutional Psychology. By making use of Bleger's perspective of the work into institutional contexts, it is presented an experience developed in a specific institution, located in Nova Friburgo, which had as main purpose the preparation of adolescents for the local labor market. As a conclusion it is pointed out the pertinence of Institutional Psychology, since it allows not only subjective transformation, by leting the institutional actors be the agents of their lives, as well as institutional transformation, by making its dynamic more flexible and less focused on authority.

Key words: Psychology, Institutional Psychology, institution.

O desenvolvimento do estágio supervisionado durante o curso de graduação em Psicologia é de singular importância na formação acadêmica de seus alunos. Certamente, aquele configura o primeiro momento em que eles podem promover, por si mesmos, a confrontação entre aquilo que vêm construindo no campo teórico e a aplicabilidade deste em uma prática concreta, que se apresenta, sempre, singular, confusa, inquietante, angustiante e inusitada. Porém, para além das dificuldades, ou talvez por causa delas, tais experiências re-configuram nosso universo de percepções e nos permitem refletir sobre o significado de nossa profissão.

É sobre um desses ricos momentos que o presente artigo trata. Nele trazemos, como ilustração e como ponto de ancoragem, o relato de uma experiência em que tivemos a oportunidade de desenvolver o estágio curricular supervisionado do Curso de Graduação em Psicologia da Universidade Estácio de Sá, da cidade de Nova Friburgo, Rio de Janeiro, em uma instituição voltada para a profissionalização de adolescentes pobres que visava ao seu ingresso no mercado de trabalho local.
A experiência a que nos referimos se iniciou a partir de um convite formulado pela instituição à Universidade, em busca da abertura de um convênio que sustentasse a prática de estágio supervisionado. A construção de tal espaço de relacionamento suscitou, a principio, uma reflexão sobre o que entendíamos como função do trabalho da Psicologia no âmbito institucional, uma prática que, embora não seja recente, apresenta inúmeras controvérsias que perpassam diferentes formas de entendimento sobre os conceitos de instituição, organização, sujeito e relações institucionais, por exemplo, que implicarão diferentes formas de se conceber a proposta de trabalho e de instrumentalização deste. Tais controvérsias passam pelas obras de Pichon-Riviere (1996), Bleger (1984; 2001), Lapassade (1977), Loureau (1975), ou Foucault, (1979; 2002), que influenciou, sobretudo, a perspectiva atual desenvolvida no Brasil por Marlene Guirado (1986; 1987), e Guillon de Albuquerque (1978), o que demonstra a enorme disparidade entre as propostas de se trabalhar em instituições a partir da Psicologia. Tal fato nos impôs, então, a necessidade de promover uma escolha teórica precisa, porque desta dependeria o entendimento e o 
É importante frisar que o psicólogo que optapor trabalhar no âmbito da psicohigiene é colocado diante do desafio de não constituir outra instituição dentro daquela que se propôs a investigar. desenvolvimento de nossas ações. Por alguns motivos específicos, que recobrem o conceito de instituição, de sujeito, de proposta de trabalho e de instrumentalização deste, nossa escolha recaiu sobre a perspectiva da Psicologia institucional concebida e desenvolvida por José Bleger, autor que, ao inscrever seu trabalho no âmbito da psicohigiene, propõe que este deva ser efetuado não sobre as individualidades, mas sobre o campo das inter-relações constituídas nas redes institucionais cristalizadas, objetivando uma flexibilização destas.

Dessa forma, nosso relato se inicia pela apresentação da perspectiva da Psicologia institucional proposta por Bleger para, em seguida, passarmos à apresentação de nossa própria experiência com um grupo de jovens que freqüentava a referida instituição. Nossa esperança é que, ao darmos vida às nossas argumentações, o leitor perceba, por si mesmo, toda a riqueza de um trabalho que, se, por um lado, suscita resistências poderosas, por outro, se faz (re)construtor do sujeito e também da realidade que o cerca.

\section{Psicohigiene e Psicologia institucional: a configuração de um campo de trabalho}

Segundo Bleger (1984), a mudança de paradigma em relação à atuação do psicólogo, do âmbito individual, privado e, portanto, relacionado aos problemas psicopatológicos, para ingressar no campo da promoção da saúde, abriu um leque de novas possibilidades de atuação para a prática da Psicologia: grupos, instituições e comunidades. Trata-se aqui da passagem salientada pelo autor do âmbito da higiene mental para o da psicohigiene. Nesse sentido, o autor salienta que, para o psicólogo, uma instituição interessará como organismo específico e concreto, mas sem perder de vista que seu objetivo é o de "estudar os fenômenos humanos que se dão em relação com a estrutura, a dinâmica, as funções e os objetivos da instituição" (Bleger,1984, p.37). É importante frisar que o psicólogo que opta por trabalhar no âmbito da psico-higiene é colocado diante do desafio de não constituir outra instituição dentro daquela que se propôs a investigar. Isso significa que o psicólogo a serviço da psicohigiene não deve introduzir outro modelo de organização e normatização como gabinetes, consultórios ou até mesmo laboratórios. Dessa forma, a postura de permanente investigação é condição fundamental para o aperfeiçoamento da Psicologia institucional, como disciplina e como método clínico.

Assim sendo, "todos os fatores que compreendem a investigação e a ação devem ser incluídos como variáveis do fenômeno mesmo que se estuda e que se vai modificando enquanto se estuda. Cada passo dado na ação deve, por sua vez, ser investigado em seus efeitos, incluindo o fato de que sua própria investigação já é uma atuação" (Bleger,1984, p.25).

Essa perspectiva demonstra a concepção do autor de que a investigação e o desenvolvimento científico não se desvinculam do trabalho concreto, mas, ao contrário, são condições inerentes ao fazer de cada um. Desse modo, o autor propõe uma forma de fazer ciência em decorrência da qual "a Psicologia institucional (prática) não será mera aplicação da Psicologia (ciência) mas sim, uma forma de fazer Psicologia enquanto ciência e enquanto profissão (Guirado, 1986, p. 7).

Nesse sentido, cabe aqui promover uma diferenciação entre Psicologia institucional e Psicologia em uma instituição. Para Bleger (1984), esta última configura uma prática na qual o psicólogo (na condição de empregado) se limita a executar tarefas determinadas pela própria instituição. Por sua vez, para o psicólogo institucional, o vínculo empregatício com a instituição precisa ser constituído de tal forma que lhe garanta uma autonomia que o permita 
projetar sua tarefa, em função de o diagnóstico ser efetuado a partir de suas investigações iniciais, sendo nesse aspecto que o psicólogo se coloca diante da questão ética de ter que lidar com os objetivos da instituição e dos seus próprios. Reafirma-se que, vinculado aos preceitos da psicohigiene, o psicólogo institucional deverá trabalhar como "um técnico da relação interpessoal, dos vínculos humanos, um técnico da explicitação do implícito. Sua função não será jamais a de decidir ou de resolver os problemas da instituição nem de executar as ações decididas pelos grupos" (Guirado,1986, p.35).

A decisão de um psicólogo em trabalhar em uma instituição implica, antes de mais nada, um levantamento dos objetivos específicos da mesma e os meios pelos quais ela busca alcançar tais objetivos. Os estudos de tais objetivos institucionais, de suas dinâmicas e conseqüências incluem também aqueles que levaram a instituição a solicitar a intervenção profissional de um psicólogo. Torna-se necessário investigar as fantasias que a instituição constrói acerca daquilo o psicólogo faz ou poderá fazer em suas dependências, pois a atuação desse profissional promove ansiedades de tipos e graus variados, que implicarão um manejo específico no sentido de ultrapassar as resistências que tentarão impedir a sua ação, posto que " o psicólogo é um agente de mudança e um catalisador ou depositário de conflitos, e, por isso, as forças operantes na instituição irão agir no sentido de anular ou amortizar suas funções e sua ação" (Bleger,1984, p.53).

Para Bleger, não interessa estudar o papel das instituições no desenvolvimento da personalidade de cada indivíduo que nela trabalha, mas sim, a dinâmica psicológica que nela se desenvolve, na medida em que, por um lado, o indivíduo tem sua personalidade afetada pela dinâmica institucional e, por outro, é parte integrante da mesma e deposita uma parcela de sua personalidade nas redes institucionais. Assim, a instituição oferece ao indivíduo um suporte à sua personalidade e deve ser um espaço que ofereça meios de crescimento e de desenvolvimento da personalidade. Quanto mais fragilizada e pouco integrada a personalidade de cada indivíduo se apresentar, mais o sujeito precisará desse suporte e mais dependente será da instituição. É fácil perceber que, nessas circunstâncias, a mudança proposta pela Psicologia institucional parecerá bastante ameaçadora, isso porque, ao mesmo tempo em que a instituição funciona como meio de organização, regulação e controle social, ela é um instrumento de equilíbrio da personalidade. Nesse sentido, podemos entender que a instituição apresenta processos de reparação e de defesa contra as ansiedades, tornando-se, assim, depositária das partes mais imaturas da personalidade dos indivíduos que nelas trabalham. Por essas razões, o trabalho da Psicologia necessita ser efetuado com muita delicadeza, de modo a não suscitar resistências capazes de anulá-lo.

Objetivando o trabalho institucional, cabe ao psicólogo detectar os pontos de urgência a serem trabalhados a partir de técnicas grupais, pontuando que, em todos os grupos, há "um tipo de relação que é, paradoxalmente, uma não relação, no sentido de uma nãoindividuação, que se impõe como matriz ou como estrutura básica de todo o grupo" (Bleger, 1984, p.102). A essa forma de relação grupal, o autor denominou sociabilidade sincrética, em contraponto à sociabilidade por interação, na qual os indivíduos se relacionam de uma forma através da qual há maiores recursos para se promover relações de complementaridade e de aceitação das diferenças. Quanto mais um grupo assuma a condição de uma organização, tanto mais sua finalidade será a de existir por si próprio, deixando de lado os objetivos pelos quais se originou. Esse fenômeno é considerado, por Bleger (2001), uma lei geral das organizações: "Em todas elas, os objetivos explícitos para os quais foram criadas correm sempre o risco de passar a um segundo plano, passando ao
A decisão de um psicólogo em trabalhar em uma instituição implica, antes de mais nada, um levantamento dos objetivos específicos da mesma e os meios pelos quais ela busca alcançar tais objetivos 
"Uma das maiores virtudes de um grupo operativo é a possibilidade que oferece de aprender a agir, pensar e fantasiar com liberdade, a reconhecer o nexo estreito e sutil da passagem que existe entre imaginar, pensare propor hipóteses cientificas"

Bleger primeiro plano a perpetuação da organização como tal" (p.15).

É nesse sentido que, para o autor, as organizações são parte integrante da personalidade do indivíduo, entendendo que o ser humano é, antes de ser uma pessoa individualizada, um grupo, posto que sua personalidade é o próprio grupo, já que as instituições e organizações são depositárias das partes sincréticas da personalidade de cada um. Isso significa que toda mudança ocorrida na estrutura institucional representa uma mudança individual de seus integrantes, o que explica, em grande parte, a enorme resistência imposta pelos membros de uma instituição ao trabalho proposto pela Psicologia institucional.

Partindo da perspectiva aberta por PichonRivière, Bleger propõe um trabalho com grupos operativos, os quais possuem objetivos, problemas e conflitos que devem ser estudados e considerados pelo próprio grupo na medida em que vão aparecendo, de tal forma que:

"Uma das maiores virtudes de um grupo operativo é a possibilidade que oferece de aprender a agir, pensar e fantasiar com liberdade, a reconhecer o nexo estreito e sutil da passagem que existe entre imaginar, pensar e propor hipóteses científicas" (Bleger, 2001, p.75).

Sendo assim, as ansiedades e tensões estarão envolvidas no processo criador, uma vez que envolvem a perda de estereotipias que proporcionam um controle seguro da situação pelos indivíduos envolvidos no processo.

No entanto, na medida em que a atuação do psicólogo no grupo é sobre os esquemas referenciais, a fim de romper com as estereotipias, um certo grau de ansiedade servirá como indicador de que seu trabalho está em andamento. Esse movimento se processa na medida em que os esquemas referenciais podem ser concebidos como o conjunto de conhecimentos e afetos com os quais o sujeito pensa e atua no interior das instituições, de tal forma que, quanto mais rígidos e cristalizados forem os esquemas referenciais, mais limitadas serão as possibilidades dos integrantes do grupo em agir racionalmente. A finalidade do grupo será, então, a de fornecer possibilidades de construção de esquemas referenciais mais plásticos, que permitam, a cada sujeito, produzir contínuas retificações, modificações e aperfeiçoamento. Deve-se lembrar sempre que tais mudanças só podem ocorrer a partir do desejo dos próprios sujeitos envolvidos no trabalho grupal e jamais para atender às expectativas do profissional.

Respeitar o emergente do grupo, ou seja, trabalhar com a informação que o grupo atualiza a cada momento e que corresponde ao que momentaneamente pode admitir e elaborar. 'Respeitando o emergente, mantémse e trabalha-se à distância com o objeto de conhecimento que o grupo pode tolerar" (Bleger, 2001, p. 83).

O autor, ao oferecer diretrizes norteadoras claras para o trabalho institucional, demonstra a proximidade e o comprometimento entre teoria e prática. Assim, é possível afirmar que a psicohigiene é um fazer constantemente preocupado com o meio no qual está inserido e é também determinado por esse meio. São esses os elementos que nortearam o trabalho que tivemos a oportunidade de desenvolver em Psicologia institucional no interior de uma instituição específica, na cidade de Nova Friburgo, Estado do Rio de Janeiro.

\section{Relato de uma experiência em Psicologia institucional: re- significando relações, re- significando vidas}

A instituição na qual nossa experiência se realizou é uma associação civil de direito 
privado, sem fins lucrativos, religiosos ou políticos, que oferece, de forma inteiramente gratuita, cursos profissionalizantes, com a finalidade de orientar e inserir adolescentes entre catorze e dezoito anos, de ambos os sexos, no mercado de trabalho local. Para tal, os jovens, após freqüentarem um curso de relações humanas e uma das oficinas profissionalizantes na instituição, podem ser encaminhados para um estágio laborativo dentro de uma empresa cadastrada, onde exercem atividades específicas sob a supervisão direta de chefes de departamentos, havendo a possibilidade de serem contratados após completarem dezoito anos. Para sua manutenção, a instituição recebe $20 \%$ a $25 \%$ da bolsa-estágio, paga a cada jovem pelas empresas colaboradoras. Além dessa porcentagem, que constitui sua principal fonte de arrecadação, a instituição pode receber doações de pessoas físicas e jurídicas e pode contar, também, com um corpo de sócios contribuintes.

O nosso trabalho se iniciou a partir de um pedido da própria instituição, que procurou a Universidade para propor uma parceria a fim de abrir oportunidades de estágios para diversos cursos de graduação. Inicialmente, duas reuniões ocorreram entre a direção da instituição, a professora universitária responsável pela supervisão dos estagiários do curso de Psicologia e os alunos de Psicologia que iriam iniciar o estágio supervisionado. Nessas reuniões, a proposta institucional foi apresentada, ficando reforçado o interesse desta em que a Psicologia fizesse um trabalho individualizado, psicoterapêutico, com alguns alunos que se mostravam mais indisciplinados e rebeldes. De nossa parte, colocamos a necessidade de termos um tempo para conhecer a instituição, os adolescentes e o trabalho que poderíamos, então, oferecer. Tal estratégia nos permitiu recusar a proposta de oferecer um atendimento psicoterapêutico, posto não ser esse o objetivo da Psicologia institucional, ao mesmo tempo em que contornávamos a primeira resistência ao nosso trabalho na medida em que a instituição tentava nos imputar um procedimento a ser seguido. Nossa proposta de trabalho, seguindo os ensinamentos de Bleger, situava-se no trabalho com a dinâmica institucional, a partir da qual uma transformação nas redes interpessoais pudesse ocorrer. Esse momento inicial de espera e observação se mostrou imprescindível para que pudéssemos identificar o ponto de urgência a ser trabalhado.

No decorrer desse período, um grupo de jovens chamou nossa atenção. Eles estavam sempre pelos corredores, nas tardes em que íamos à instituição, sem nada fazer. Soubemos, então, tratar-se das turmas que já haviam completado os cursos de relações humanas e profissionalizantes e estavam à espera de serem encaminhadas a uma empresa. A ida à instituição se fazia obrigatória para que esse encaminhamento pudesse ser efetuado, porém, como o número de vagas supera o número de candidatos, alguns jovens retornavam à instituição, sem sucesso, inúmeras semanas e meses, o que, para muitos, se transformava em uma espera angustiante e frustrante. Acreditamos ter encontrado aí um ponto de urgência a ser trabalhado, uma vez que, através de nossa intervenção, talvez pudéssemos oferecer a esses jovens um espaço para falar e entrar em contato com as suas necessidades e preocupações, objetivando a criação de novas formas de elaboração e de interação com seus problemas e suas vidas.

Iniciamos, então, um trabalho com esse grupo de jovens propondo encontros semanais, nos quais algumas dinâmicas seriam introduzidas e trabalhadas. Diante do desconhecido, tanto para eles quanto para nós, percebemos que o enquadramento das atividades não é apenas um estabelecimento das variáveis que influenciam a investigação e a intervenção, mas é, antes de tudo, um contrato de confiança. A resistência do grupo em participar das 
É interessante observar que os integrantes desse grupo inicial eram tidos, pela instituição, como os mais difíceis de serem encaminhados a uma empresa, e, por isso,

permaneciam excluídos e segregados dentro da própria instituição. atividades sugeridas foi o primeiro obstáculo com que nos deparamos. Os jovens, ao serem convidados a falarem de si mesmos, de seus sonhos e expectativas diante da vida, respondiam com o silêncio. Foi quando percebemos o quanto deveria ser difícil para eles falarem de algo sobre o qual ninguém lhes havia perguntado até então e sobre o qual não possuíam nenhuma noção. Tal movimento nos apontava também o lugar no qual a instituição os colocava, posto que, a eles, não era dada a possibilidade de interlocução diante da imposição de regras e leis explícitas.

É interessante observar que os integrantes desse grupo inicial eram tidos, pela instituição, como os mais difíceis de serem encaminhados a uma empresa, e, por isso, permaneciam excluídos e segregados dentro da própria instituição. Tal segregação foi claramente observada durante os encontros semanais do grupo, na medida em que este se dividia abertamente em dois segmentos: um, dos meninos bem comportados e bem vistos pela instituição, e outro, dos meninos malvistos e rebeldes. Dessa mesma forma, em nossos encontros, os jovens do primeiro grupo sempre se mostravam dispostos a participar das atividades, enquanto os jovens do segundo grupo permaneciam inertes e desmotivados. Foi interessante observar que esses jovens, ao notarem a participação das estagiárias nas atividades propostas, ou seja, ao perceberem a implicação das mesmas no desenrolar do grupo, se "arriscaram" a fazer o mesmo, desencadeando, a partir daí, um processo de transformação tanto interno quanto institucional, processo que teve, como primeiro movimento, a escolha de um nome para o grupo: GRUPO JOVEM, o que marcou o momento inicial da construção de uma identidade própria, aspecto fundamental para que esses jovens começassem a se perceber como cidadãos.

Gradativamente, a atuação da Psicologia começou a fazer parte da rotina da instituição, o que provocou, por seu turno, algumas formas de resistência visíveis: a interrupção das atividades em andamento, embora um papel na porta avisasse que o grupo estava em trabalho, o uso do espaço reservado para o grupo para outras atividades, e, principalmente, o pedido expresso pela instituição de que a Psicologia participasse de atividades programadas pela própria instituição (tais como a seleção de novos alunos, entrevistas com os pais dos mesmos, a construção de um questionário para levantamento de banco de dados sobre os alunos, etc), fatores esses que apenas apontavam uma repercussão do nosso trabalho em nível institucional.

Um dos temas surgidos a partir das atividades do grupo dizia respeito à escolha profissional e ao planejamento de vida futura. Nesse momento, a fala de um jovem se mostrou fundamental para o direcionamento de nosso trabalho: "Não somos nós que escolhemos, nós somos escolhidos", palavras que pareciam resumir o sentimento geral do grupo, sua posição de passividade e impotência diante dos acontecimentos de suas vidas. Os jovens assumiram a postura de vítimas e culparam o(s) outro (s) por sua situação. Embora não possamos perder de vista as dificuldades reais que os jovens das classes desfavorecidas enfrentam no cotidiano brasileiro, acreditamos que, naquele momento, seria importante propor a discussão de tal situação, visando a construir alternativas possíveis de transformação. Começamos, então, a pensar, em grupo, na questão do projeto de vida e nos aspectos envolvidos nas nossas escolhas diárias, nas suas implicações e conseqüências. Nesse momento, o grupo percebeu que, por menores que sejam, há sempre escolhas a serem efetuadas, escolhas essas que podem levar nossas vidas a ganhar múltiplos caminhos. Pensar no futuro de suas vidas levou o grupo a refletir sobre o tema das profissões, tanto em nível universitário quanto técnico, o que evidenciou o alto grau de desinformação 
acerca do que é preciso para obtê-las. Nesse momento, o grupo assumiu uma postura de indagação operativa, transcendendo o tema da escolha profissional propriamente dita para ingressar nas questões institucionais, manifestando claramente suas dúvidas e insatisfações em relação ao processo de seleção dos candidatos às vagas nas empresas e relatando as dificuldades e frustrações que vivenciavam quando não eram encaminhados para nenhuma entrevista. Apontamos aqui a relevância desse momento, pois pôde-se perceber uma nítida mudança de posicionamento desses jovens em relação às suas vidas na medida em que assumiram um posicionamento interrogativo e ativo sobre os fatos que vivenciavam em seu dia a dia. $\mathrm{O}$ espaço grupal havia sido construído, e os jovens o estavam aproveitando, cada qual a seu modo e segundo as suas características individuais. Esse ambiente permitiu que arriscássemos uma atividade mais audaciosa, na qual os jovens precisariam se expor um pouco mais: montamos um teatro de sombras e pedimos que improvisassem algumas cenas que os espectadores deveriam adivinhar quais eram. A adesão foi total, e, como conseqüência, surgiram, num segundo momento, novas profissões em seus repertórios de possibilidades e, como não poderia ser, a de ator, fato bastante significativo se pensarmos no sentido de ator como agente, ou seja, agente de suas próprias vidas.

Durante todo o trabalho grupal, a questão da informação sobre as profissões, em como obtêlas, e por que, constituiu-se em um tema recorrente nas atividades, fator esse que nos motivou a fazer um círculo de palestras, convidando profissionais de diversas áreas para falarem sobre suas atividades. Diante dessa oportunidade, os jovens aproveitaram para tirar suas dúvidas, demonstrando terem, definitivamente, assumido uma nova postura diante da vida.

Após um período de dois meses de férias, retornamos o trabalho com o grupo enfrentando algumas dificuldades. A instituição impôs que a participação dos jovens no grupo deixasse de ser opcional e passasse a ser obrigatória, como pré-requisito para serem encaminhados às empresas. A obrigatoriedade da presença trouxe conseqüências específicas: o aumento significativo no número de participantes, fato que impedia uma escuta mais individualizada de cada sujeito, e a recusa na participação das atividades propostas. A alternativa que encontramos foi a de formar subgrupos, que nos permitiriam manter $\mathrm{o}$ trabalho em andamento.

Por outro lado, ultrapassando as indicações individuais, a questão da obrigatoriedade remetia, novamente, ao âmbito institucional e à forma impositiva e desqualificante com que a instituição tratava seus jovens. Tal movimento (re)produzia, de certa forma, a mesma dinâmica social segregadora e excludente com a qual esses jovens se vêem confrontados diariamente em suas vidas. Nesse ponto, uma transformação operada pelo grupo foi crucial. Diante da resistência em participar das atividades propostas pelas estagiárias, foi aberta uma discussão sobre o tema. Os jovens começaram, então, a dar suas opiniões sobre o grupo e sobre quais atividades gostariam de desenvolver. Após uma votação, as propostas do grupo foram levadas para a direção da instituição, o que permitiu a reavaliação de algumas regras institucionais e o alcance de um consenso. Nesse processo, os jovens puderam experienciar uma atitude ativa e responsável diante de um problema a ser solucionado. Por seu turno, a instituição também abriu um espaço para rever e reformular suas atitudes e regras perante aqueles jovens.

Nesse ponto, cabe, certamente, um olhar para os objetivos da instituição: sua finalidade maior é a de inserir adolescentes pobres no mercado de trabalho local, atendendo, assim, uma necessidade da comunidade e das famílias de terem mais um membro empregado. É 
interessante, aqui, destacar o discurso que constitui, subliminarmente, as redes simbólicas a partir das quais a instituição e seus atores se percebem: a instituição é pobre e, portanto, não possui recursos financeiros suficientes para a ampliação de seus quadros profissionais e para realizar melhorias em seus cursos. Há um pedido explícito a todas as pessoas (inclusive funcionários) para que façam doações de materiais e trabalho voluntário. Esse discurso perpassa a instituição - pobre, carente, necessitada, sem possibilidades de transformação - e o adolescente que dela se beneficia - pobre, carente, passivo e desamparado. Assim, quando ouvimos dos jovens que o maior valor do trabalho é o dinheiro que esse pode proporcionar, e ouvimos, da instituição, que a prioridade é empregar os jovens, pois somente através da bolsa-estágio a instituição pode se manter, percebemos que a prioridade institucional não estava na formação profissional desses jovens, mas na manutenção da própria instituição. Sendo assim, fica claro aquilo que Bleger (2001) pontuou: "o grupo se burocratizou, entendendo por burocracia a organização na qual os meios se transformam em fins, e deixase de lado o fato de se ter recorrido aos meios para conseguir determinados objetivos ou fins" (p.115).

Segundo o que nos informa o autor, toda instituição tende a ter a mesma estrutura que o problema que deve enfrentar e para o qual foi criada. Desse modo, foi-nos possível compreender a dinâmica institucional, que, diante da percepção de jovens ativos, capazes de se posicionarem diante de um problema a ser resolvido, que deixavam de ser objetos passivos para se tornarem sujeitos de suas ações e atos, se viu obrigada a reformular suas próprias convicções e objetivos. Esse fato, como era esperado, levou à emergência de inúmeras estratégias de resistência através de sucessivas atuações institucionais de desvalorização de nosso trabalho. Tais atitudes, no entanto, serviram para mostrar o quanto nosso trabalho grupal estava sendo produtivo como agente mobilizador e transformador, tanto no âmbito subjetivo quanto institucional.

\section{Algumas reflexões...}

Para pensar a nossa experiência com a Psicologia institucional, adotamos a perspectiva da psicohigiene, proposta por Bleger para nortear nosso trabalho, na medida em que nesta, a Psicologia institucional se propõe a intervir nas formas estereotipadas e alienadas que os relacionamentos interpessoais assumem nos grupos, nas organizações e nas instituições, impedindo que os indivíduos se constituam como agentes de suas próprias ações e escolhas.

Após um ano e meio de contínuo trabalho em uma instituição, foi-nos possível perceber tanto as possibilidades quanto os limites intrínsecos na tarefa de promover uma re-significação das relações cristalizadas dento de uma instituição. Percebemos, ainda, o quanto esse processo é capaz de mobilizar não somente o grupo envolvido nas atividades mas também a instituição como um todo. Assim, por mais difícil que essa tarefa se torne em certos momentos, é fato que a Psicologia institucional é uma abordagem possível e uma oportunidade singular de crescimento emocional para seus envolvidos. Nossa experiência nos demonstrou, acima de tudo, a importância e a pertinência de se utilizar o trabalho da psicologia a partir de uma perspectiva que possibilita e incentiva o florescimento de novas configurações institucionais e subjetivas. 

Universidade Estácio de Sá, Nova Friburgo. Estrada Vr. Eugênio Guilherme Spitz, 2681, Mury, Nova Friburgo, R.J. Cep: 28615-450 Tel.: (22) 25422100; (22) 92142809. E-mail: patriciagula@yahoo.com.br.

Nadja Pinheiro Psicóloga, Mestre em Psicologia (UFRJ), Doutora em Psicologia (Puc-Rio), professora-adjunta do Departamento de Psicologia da Universidade Federal do Paraná (UFPR), pesquisadora do Núcleo de Estudos de Desenvolvimento Humano (NEDHU-UFPr). Universidade Federal do Paraná, Praça Santos Andrade, 50, Centro. Curitiba, Paraná. Cep:80060-240. Tel.: (41) 33102625. E-mail:nadjanbp@rjnet.com.br; nadjanbp@ufpr.br

BLEGER, J. Psico-higiene e Psicologia Institucional. Porto Alegre: Artes Médicas, 1984.

Temas de Psicologia: Entrevistas e Grupos. São Paulo: Martins Fontes, 2001.

FOUCAULT, M. Microfísica do Poder. Rio de Janeiro:Graal, 1979. . Vigiar e Punir: História da Violência nas Prisões.

Petrópolis:Vozes, 2002.

GUILON DEALBUQUERQUE, J.A. Metáforas da Desordem. Rio de Janeiro: Paz e Terra, 1978.

GUIRADO, M. Instituições e Relações Afetivas: o Vínculo com o Abandono. São Paulo: Summus, 1986.
Psicologia Institucional. São Paulo: EPU, 1987.

\section{Referências} GULA, P. O Paraíso Infernal: uma Experiência em Psicologia Institucional. Monografia de conclusão de curso. Graduação em Psicologia, Universidade Estácio de Sá, Nova Friburgo, 2003.

LAPASSADE, G. Grupos, Organizações e Instituições. Rio de Janeiro: Francisco Alves, 1977.

LOURAU, R. A Análise Institucional. Petrópolis: Vozes, 1975. PICHON-RIVIÈRE, E. O Processo Grupal. São Paulo: Martins Fontes, 1996.

PINHEIRO, N. Uma Casa com Paredes de Cristal: a Clínica Psicanalítica no Ambulatório Hospitalar. Tese de doutorado. Departamento de pós-graduação em Psicologia Clínica, Pontifícia Universidade Católica, Rio de Janeiro, 2003. 